Check for updates

Cite this: RSC Adv., 2017, 7, 44009

Received 6th July 2017

Accepted 16th August 2017

DOI: $10.1039 / \mathrm{c} 7 \mathrm{ra07442e}$

rsc.li/rsc-advances

\section{Acid-promoted oxidative methylenation of 1,3- dicarbonyl compounds with DMSO: application to the three-component synthesis of Hantzsch-type pyridines $\dagger$}

\author{
LuLu Xue, ${ }^{\mathrm{b}}$ Guolin Cheng, ${ }^{\text {*a }}$ Ruifeng Zhu ${ }^{\mathrm{b}}$ and Xiuling Cui (D) *b
}

\begin{abstract}
A highly convergent one-pot synthesis of Hantzsch-type pyridines has been developed based on a threecomponent annulation of 1,3-dicarbonyl compounds, DMSO, and ammonium salt. A transition-metal-free oxidative methylenation reaction/Hantzsch pyridine synthesis cascade reaction was involved in this process. This intermolecular annulation reaction proceeds under mild reaction conditions, wherein DMSO serves as solvent, carbon source, and oxidant. A series of polysubstituted pyridines and methylene-bridged bis-1,3-dicarbonyl compounds were prepared in high yields.
\end{abstract}

Methylene-bridged bis-1,3-dicarbonyl compounds are useful building blocks or intermediates in organic synthesis. ${ }^{1}$ Traditionally, these compounds are synthesized from bis-1,3dicarbonyl compounds by using $\mathrm{CH}_{2} \mathrm{Br}_{2}$ (ref. 2) or formaldehyde $^{3}$ as one-carbon sources with low efficiency. Meanwhile, these compounds were constructed by using $N$-methyl compounds as one-carbon sources through transition-metal catalysed methylenation reactions, such as $\mathrm{Ru},{ }^{4} \mathrm{Cu} / \mathrm{Au},{ }^{5}$ and $\mathrm{Fe},{ }^{6}$ as well as through $\mathrm{K}_{2} \mathrm{~S}_{2} \mathrm{O}_{8}$ (ref. 7) oxidative methylenation reactions (Scheme 1a). However external oxidants are always required.

Over the past decades, the solvent-participated reaction is considered as an important strategy for the developing economic chemical methodologies. As a less toxic and inexpensive solvent, dimethyl sulfoxide (DMSO) is commonly employed as an effective oxidant ${ }^{8}$ and the source of $-\mathrm{SMe}{ }^{9}$ $-\mathrm{SOMe}^{10}{ }^{16}-\mathrm{SO}_{2} \mathrm{Me},{ }^{11}-\mathrm{CH}_{2} \mathrm{SMe},{ }^{12}-\mathrm{CN},{ }^{13}-\mathrm{CHO},{ }^{14}=\mathrm{CH}_{2},{ }^{15}$ $-\mathrm{CH}_{2}{ }^{-16}$ and $-\mathrm{Me}^{17}{ }^{17}$ We have recently developed a method to 1,3,5-triarylbenzenes ${ }^{18 a}$ and bis( $1 H$-indol-yl)methanes, ${ }^{18 b}$ in which DMSO served as a precursor of methine and methylene unit, respectively. Despite those advantages, the using of DMSO as methine source is still rare. ${ }^{19}$ We hypothesisd that DMSO could be used as methylenation reagent instead of $N$-methyl compounds to form methylene-bridged bis-1,3-dicarbonyl

${ }^{a}$ College of Materials Science \& Engineering, Huaqiao University, Xiamen 361021, China.E-mail: glcheng@hqu.edu.cn

${ }^{b}$ Engineering Research Center of Molecular Medicine, Ministry of Education, Key Laboratory of Molecular Medicine of Fujian Province, Key Laboratory of Xiamen Marine and Gene Drugs, Institutes of Molecular Medicine and School of Biomedical Sciences, Huaqiao University, Xiamen, 361021, China. E-mail: cuixl@hqu.edu.cn $\dagger$ Electronic supplementary information (ESI) available. CCDC 1560452. For ESI and crystallographic data in CIF or other electronic format see DOI: 10.1039/c7ra07442e compounds, which could be further trapped with ammonium salt leading to Hantzsch-type pyridines. Recently, multicomponent reactions have emerged as attractive processes for the assembly of complex molecules..$^{20}$ During our ongoing investigations in constructing of heterocycle compounds, ${ }^{21}$ herein, we wish to report an efficient protocol for the synthesis of Hantzsch-type pyridines via a three-component cascade reaction of 1,3-dicarbonyl compounds, DMSO, and ammonium salt, in which two $\mathrm{C}-\mathrm{C}$ bonds and two $\mathrm{C}-\mathrm{N}$ bonds were formed in one-pot manner (Scheme 1b).

Initially, 1,3-dipheylpropane-1,3-dione $\mathbf{1 a}$ was selected as a model substrate with $\mathrm{NH}_{4} \mathrm{Cl}$ as nitrogen source in DMSO to explore the reaction efficiency (Table 1). To our delight, the desired pyridine product $\mathbf{4 a}$ was afforded in $16 \%$ yield in the

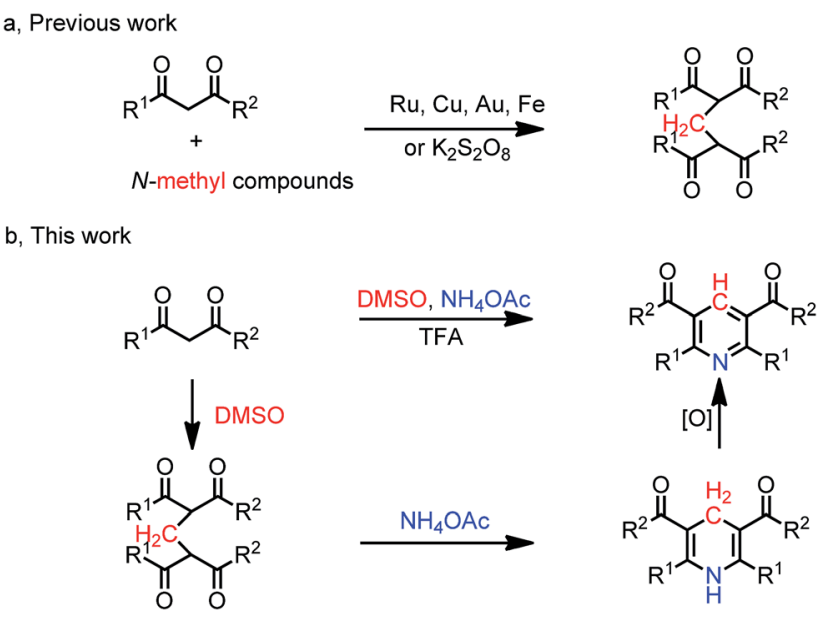

Scheme 1 Methods for the synthesis of methylene-bridged bis-1,3diketones. 
Table 1 Optimization of reaction conditions ${ }^{a}$

\begin{tabular}{|c|c|c|c|c|c|}
\hline & & $\begin{array}{l}\text { rce } 3 \\
\text { SO } \\
\longrightarrow\end{array}$ & $\mathrm{H}$ & & \\
\hline Entry & $\mathrm{N}$ source & TFA (eq.) & Temp. $\left({ }^{\circ} \mathrm{C}\right)$ & $T(\mathrm{~h})$ & Yield $^{b}(\%)$ \\
\hline 1 & $\mathrm{NH}_{4} \mathrm{Cl}$ & 12 & 100 & 24 & 16 \\
\hline 2 & $\mathrm{NH}_{4} \mathrm{Cl}$ & 12 & 120 & 24 & 37 \\
\hline 3 & $\mathrm{NH}_{4} \mathrm{Cl}$ & 12 & 140 & 24 & 30 \\
\hline 4 & $\mathrm{NH}_{4} \mathrm{Cl}$ & 6 & 120 & 24 & 71 \\
\hline 5 & $\mathrm{NH}_{4} \mathrm{Cl}$ & 3 & 120 & 24 & 31 \\
\hline 6 & $\mathrm{NH}_{4} \mathrm{Cl}$ & 6 & 120 & 24 & $73^{c}$ \\
\hline 7 & $\mathrm{NH}_{4} \mathrm{Cl}$ & 6 & 120 & 24 & $56^{d}$ \\
\hline 8 & $\mathrm{NH}_{4} \mathrm{OH}$ & 6 & 120 & 24 & 78 \\
\hline 9 & $\mathrm{NH}_{4} \mathrm{HCO}_{3}$ & 6 & 120 & 24 & 62 \\
\hline 10 & $\mathrm{NH}_{4} \mathrm{OAc}$ & 6 & 120 & 24 & 83 \\
\hline 11 & $\mathrm{NH}_{4} \mathrm{OAc}$ & 6 & 120 & 48 & 97 \\
\hline 12 & $\mathrm{NH}_{4} \mathrm{OAc}$ & 0 & 120 & 24 & np \\
\hline 13 & $\mathrm{NH}_{4} \mathrm{OAc}$ & 6 & 120 & 48 & $56^{e}$ \\
\hline 14 & $\mathrm{NH}_{4} \mathrm{OAc}$ & 6 & 120 & 48 & $81^{f}$ \\
\hline
\end{tabular}

${ }^{a}$ General conditions: $1 \mathrm{a}(0.5 \mathrm{mmol})$ and $3 \mathrm{a}(1.0 \mathrm{mmol})$ with TFA in $2 \mathrm{~mL}$ DMSO under air. ${ }^{b}$ Isolated yield. ${ }^{c} 3.0$ equiv. of $3 a .{ }^{d} 1.0$ equiv. of $3 a$. ${ }^{e}$ The reaction was carried out under $\mathrm{N}_{2} .{ }^{f} \mathrm{AcOH}$ was used instead of TFA.

presence of TFA as an additive (entry 1). The configuration of $\mathbf{4 a}$ was determined by single crystal X-ray diffraction analysis. With this preliminary result in hand, we continued to optimize the reaction conditions. Gratifyingly, increasing the reaction temperature resulted in a positive effect on the reaction (entry $2)$. However, higher temperature $\left(140{ }^{\circ} \mathrm{C}\right)$ gave slight poorer result (entry 3). When the loading of TFA was decreased to 6 equivalents, the corresponding yield sharply enhanced from $30 \%$ to $71 \%$. Further decreasing the amount of TFA gave a reduced yield of $31 \%$ (entries 4,5 ). The formation of product was also affected by the loading of $\mathbf{3 a}$ (entries 6, 7). After a brief screening of different ammonium salts, such as $\mathrm{NH}_{4} \mathrm{OH}$, $\mathrm{NH}_{4} \mathrm{HCO}_{3}$, and $\mathrm{NH}_{4} \mathrm{OAc}$, we found that $\mathrm{NH}_{4} \mathrm{OAc}$ was the most effective nitrogen source (entries 8-10). The yield increased with the extension of the reaction time from $24 \mathrm{~h}$ to $48 \mathrm{~h}$ (entry 11). The reaction did not proceed in the absence of acid (entry 12). When the reaction was performed under $\mathrm{N}_{2}$ atmosphere, the yield was lower than that under air atmosphere (entry 13). This result clearly revealed that $\mathrm{O}_{2}$ as an oxidant sharply increased the yield and DMSO may serve as an oxidant in the absence of $\mathrm{O}_{2}$. A control experiment showed that the yield was decreased to $81 \%$ when $\mathrm{AcOH}$ was used instead of TFA (entry 14). These studies indicate that the optimal one-pot system for this annulation reaction was $1 \mathrm{a}(0.5 \mathrm{mmol}), 3 \mathbf{b}(1.0 \mathrm{mmol})$, TFA (3.0 mmol) in DMSO $(2 \mathrm{~mL})$ at $120{ }^{\circ} \mathrm{C}$ under air for $48 \mathrm{~h}$.

Having identified the reaction conditions for the synthesis of pyridine derivatives, a wide variety of substituted 1,3-dicarbonyl compounds were submitted to investigate the substrate scope and generality. As displayed in Scheme 2, the reaction exhibited

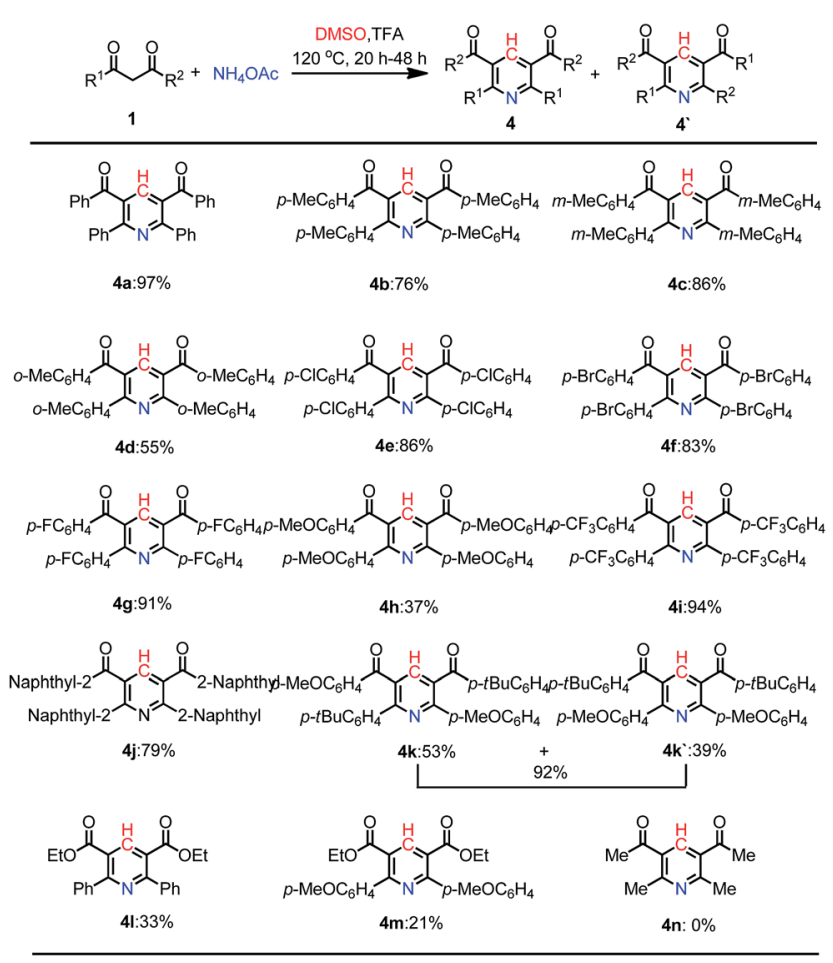

Scheme 2 Representative results.

satisfactory tolerance of the substrates containing substitutions of distinct properties, such as $\mathrm{Me}, \mathrm{MeO}, \mathrm{F}, \mathrm{Cl}, \mathrm{Br}, \mathrm{CF}_{3}$, and $\mathrm{CO}_{2} \mathrm{Me}$. The steric hindrance influenced this reaction obviously. The substrates with ortho-substituent gave lower yield than those with para- or meta-substituent (4d vs. $\mathbf{4 c}, \mathbf{4 b})$. On the other hand, 1,3-diketones with $p$-halogen-substituents reacted smoothly to provide the desired products in good yields (4e, $\mathbf{4 f}$ and 4g). In addition, substitution with strong electronwithdrawing groups such as $4-\mathrm{CF}_{3}$ was also tolerated under the reaction conditions, giving pyridine $4 \mathbf{i}$ in $94 \%$ yield. However, strong electron-donating substituent such as methoxyl gave the desired product only in $37 \%$ yield (4h). A naphthalene derivative $(\mathbf{1 j})$ reacted in the same condition, producing the corresponding $\mathbf{4 j}$ in $\mathbf{7 9} \%$ yield. From comparison with symmetrical 1,3-dione substrates, unsymmetric substrate tended to give two major products (4k and $\mathbf{4} \mathbf{k}^{\prime}$ ). Moreover, $\beta$-ketone esters reacted smoothly with $\mathrm{NH}_{4} \mathrm{OAc}$ and give the desired products in $33 \%$ and $21 \%$, respectively (4l and $\mathbf{4 m}$ ). An aliphatic 1,3-dione failed to give the corresponding product (4n).

As mentioned above, methylene-bridged bis-1,3-dicarbonyl compounds are synthetically important chemicals. Thus, we began to synthesize these compounds by using our strategy. However, in the absence of $\mathrm{NH}_{4} \mathrm{OAc}$, the desired methylenebridged bis-1,3-dicarbonyl compound 2a was obtained in only $43 \%$ yield. $\mathrm{NH}_{4} \mathrm{OAc}$ is a more suitable ammonium salt than $\mathrm{NH}_{4} \mathrm{Cl}$ or $\mathrm{NH}_{4} \mathrm{HCO}_{3}$, in the abovementioned three-component annulation reaction (Table 1 ). We thus presume that acetate anion may play a significant role in this transformation. Then, AcOH was used instead of TFA. To our delight, the use of 3 equivalent of $\mathrm{AcOH}$ in $\mathrm{DMSO}$ at $120^{\circ} \mathrm{C}$ could produce $2 \mathrm{a}$ in $97 \%$ 

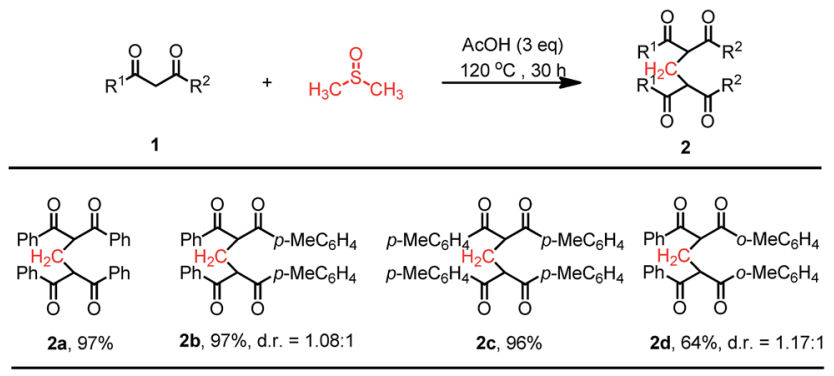

Scheme 3 Oxidative methylenation for the synthesis of methylenebridged bis-1,3-diketones.

yield. These conditions were subsequently employed when we examined the substrate scope of this reaction. Gratifyingly, a variety of 1,3-diketones 1a-d successfully reacted under the aforesaid conditions to afford the desired methylene-bridged bis-1,3-dicarbonyl compounds 2a-d in good to excellent yields (Scheme 3). Two diastereomers were obtained in ratios between 1.2 and 1 , when unsymmetric substrates were used.

Moreover, the novel pyridine compound 5 containing four different substituents could be generated from the cross-over reaction in $51 \%$ yield from 1a and 1e (eqn (1)). When benzyl amine was used as nitrogen source, the aromatic product $4 \mathbf{a}$ was obtained in $94 \%$ and the desired $N$-benzyl dihydropyridine 6 was not observed. This result suggests that the methylenation reaction/Hantzsch pyridine synthesis cascade reaction is substantially slower than the final oxidation reaction under the optimized conditions (eqn (2)).
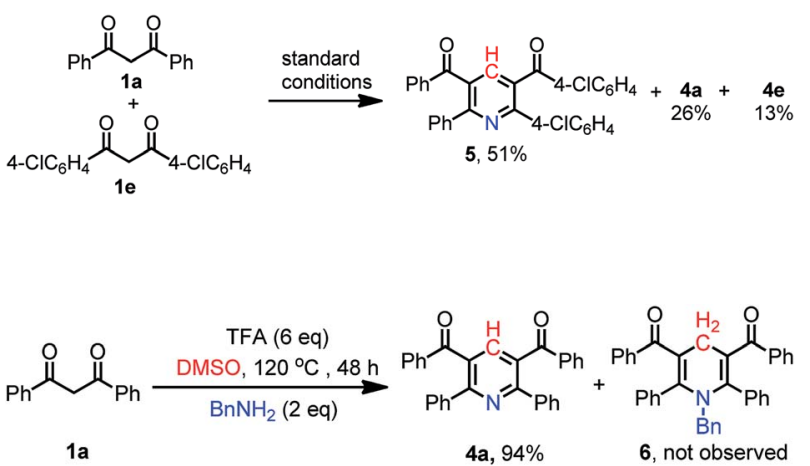

To gain more insight into the reaction mechanism, control reactions were conducted. DMSO- $d_{6}$ was used as solvent instead

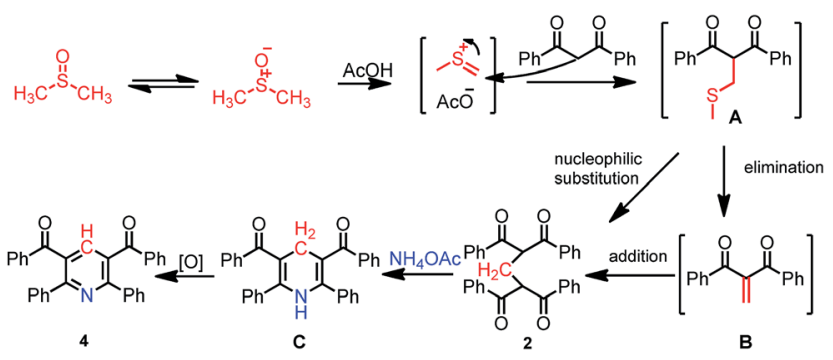

Scheme 4 Possible pathways for the reactions. of DMSO under the standard reaction conditions. D-labeled product 5 was obtained in $76 \%$ yield with $87 \%$ incorporation of deuterium, confirming that DMSO is the methylene source (eqn (3)). The radical scavengers, such as TEMPO $(2,2,6,6$-tetramethylpiperidinooxy) did not influence this reaction obviously (eqn (4)), which indicated that a radical pathway may not be involved in this reaction.

$$
\text { 1a } \quad \text { 2a- } \boldsymbol{d}_{\mathbf{2}}(87 \% \mathrm{D}), 76 \%
$$

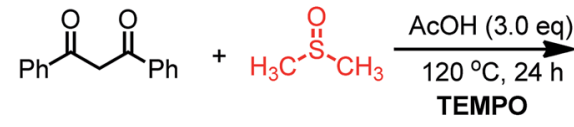

$1 a$

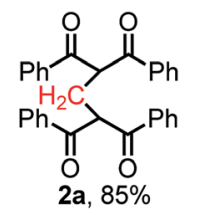

Subsequently, the proposed reaction mechanism was shown as Scheme 4. The acetate acid-promoted reaction of $\mathbf{1}$ and DMSO affords the oxidative coupling product A (Pummerer-type reaction). 2 is formed by either nucleophilic substitution reaction or the tandem reaction of elimination and Michael addition via an intermediate $\mathbf{B}^{22}$ In addition, the substituted 1,4dihydropyridine (1,4-DHP) $\mathbf{C}$ was obtained by the reaction of $\mathbf{B}$ with ammonium acetate, then via oxidation reaction to obtain the final pyridine products (Scheme 4).

\section{Conclusions}

In conclusion, we have developed a general and efficient method for the synthesis of substituted pyridines from readily available 1,3-dicarbonyl compounds. In this system, DMSO could serve as a simple, cheap solvent, and easy-to-handle one carbon source, and directly reacted with 1,3-dicarbonyl compounds to give the corresponding methylene-bridged bis1,3-dicarbonyl compounds, which could be further transformed to the Hantzsch-type pyridines in the presence of $\mathrm{NH}_{4} \mathrm{OAc}$.

\section{Conflicts of interest}

There are no conflicts to declare.

\section{Acknowledgements}

This work was NSF of China (21672075), Science and Technology Bureau of Xiamen City (3502Z20150054), Xiamen Southern Oceanographic Center (15PYY052SF01), Outstanding Youth Scientific Research Cultivation Plan of Colleges and Universities of Fujian Province (JA14012), and Promotion Program for Young and Middle-aged Teacher in Science and Technology Research of Huaqiao University (ZQN-PY120). 


\section{Notes and references}

1 (a) G. R. Newkome, G. R. Baker, S. Arai, M. J. Saunders, P. S. Russo, K. J. Theriot, C. N. Moorefield, L. E. Rogers and J. E. Miller, J. Am. Chem. Soc., 1990, 112, 8458; (b) K. Maruyama, K. Kubo, Y. Toda, K. Kawase, T. Mashino and A. Nishinaga, Tetrahedron, 1995, 36, 5609; (c) G. Kaupp, M. R. Naimi-Jamal and J. Schmeyers, Tetrahedron, 2003, 59, 3753; (d) S. Xue, Q.-F. Zhou, L.-Z. Li and Q.-X. Guo, Synlett, 2005, 2990; (e) A. Sachar, P. Gupta, S. Gupta and R. Sharma, Can. J. Chem., 2010, 88, 478.

2 Y.-S. Hon, T.-R. Hsu, C.-Y. Chen, Y.-H. Lin, F.-J. Chang, C.-H. Hsieh and P.-H. Szu, Tetrahedron, 2003, 59, 1509.

3 P. R. Blakemore, C. Kilner, N. R. Norcross and P. C. Astles, Org. Lett., 2005, 7, 4721.

4 W. J. Yoo, A. Tanoue and S. Kobayashi, Chem.-Asian J., 2012, 7, 2764.

5 R. Balamurugan and S. Manojveer, Chem. Commun., 2011, 47, 11143.

6 H. Li, Z. He, X. Guo, W. Li, X. Zhao and Z. Li, Org. Lett., 2009, 11, 4176.

7 X. Wang, Y. Wang, Y. Yuan and C.-H. Xing, Tetrahedron, 2014, 70, 2195.

8 (a) A. J. Mancuso and D. Swern, Synthesis, 1981, 1981, 165; (b) R. Chebolu, A. Bahuguna, R. Sharma, V. K. Mishra and P. Ravikumar, Chem. Commun., 2015, 51, 15438; (c) N. R. Connor, P. Bolgar and B. M. Stoltz, Tetrahedron, 2016, 57, 849.

9 (a) C. Dai, Z. P. Xu, F. Huang, Z. Yu and Y.-F. Gao, J. Org. Chem., 2012, 77, 4414; (b) S. M. Patil, S. Kulkarni, M. Mascarenhas, R. Sharma, S. M. Roopan and A. Roychowdhury, Tetrahedron, 2013, 69, 8255; (c) Z. An, Y. She, X. Yang, X. Pang and R. Yan, Org. Chem. Front., 2016, 3, 1746.

10 M. M. D. Pramanik and N. Rastogi, Chem. Commun., 2016, 52, 8557.

11 A. Shao, M. Gao, S. Chen, T. Wang and A. Lei, Chem. Sci., 2017, 8, 2175.

12 (a) J. Liu, X. Wang, H. Guo, X. Shi, X. Ren and G. Huang, Tetrahedron, 2012, 68, 1560; (b) T. Shen, X. Huang, Y.-F. Liang and N. Jiao, Org. Lett., 2015, 17, 6186.

13 X. Ren, J. Chen, F. Chen and J. Cheng, Chem. Commun., 2011, 47, 6725 .

14 (a) H. Fei, J. Yu, Y. Jiang, H. Guo and J. Cheng, Org. Biomol. Chem., 2013, 11, 7092; (b) Z. Zhang, Q. Tian, J. Qian, Q. Liu,
T. Liu, L. Shi and G. Zhang, J. Org. Chem., 2014, 79, 8182; (c) H. Cao, S. Lei, N. Li, L. Chen, J. Liu, H. Cai, S. Qiu and J. Tan, Chem. Commun., 2015, 51, 1823.

15 (a) S. Xu, Y. Gao, R. Chen, K. Wang, Y. Zhang and J. Wang, Chem. Commun., 2016, 52, 4478; (b) S. M. A. H. Siddiki, A. S. Touchy, K. Kon and K.-i. Shimizu, Chem.-Eur. J., 2016, 22, 6111.

16 (a) K. Sun, X. Wang, Y. Jiang, Y. Lv, L. Zhang, B. Xiao, D. Li, Z. Zhu and L. Liu, Chem.-Asian J., 2015, 10, 536; (b) P. Liu, Z. Shen, Y. Yuan and P. Sun, Org. Biomol. Chem., 2016, 14, 6523; (c) O. P. S. Patel, D. Anand, R. K. Maurya and P. P. Yadav, J. Org. Chem., 2016, 81, 7626.

17 (a) J. Jia, Q. Jiang, A. Zhao, B. Xu, Q. Liu, W.-P. Luo and C.-C. Guo, Synthesis, 2016, 48, 421; (b) R. Caporaso, S. Manna, S. Zinken, A. R. Kochnev, E. R. Lukyanenko, A. V. Kurkin and A. P. Antonchick, Chem. Commun., 2016, 52, 12486.

18 (a) F. Wang, J. Shen, G. Cheng and X. Cui, RSC Adv., 2015, 5, 73180; (b) P. Li, Y. Weng, X. Xu and X. Cui, J. Org. Chem., 2016, 81, 3994.

19 T. Duan, T. Zhai, H. Liu, Z. Yan, Y. Zhao, L. Feng and C. Ma, Org. Biomol. Chem., 2016, 14, 6561.

20 For the selected recently examples on multi-component cascade reaction, see: (a) W. Dai, X.-L. Jiang, J.-Y. Tao and F. Shi, J. Org. Chem., 2016, 81, 185; (b) F. Shi, G.-J. Xing, R.-Y. Zhu, W. Tan and S. Tu, Org. Lett., 2013, 15, 128; (c) F. Shi, Z.-L. Tao, S.-W. Luo, S.-J. Tu and L.-Z. Gong, Chem.Eur. J., 2012, 18, 6885; (d) F. Shi, W. Tan, R.-Y. Zhu, G.-J. Xing and S.-J. Tu, Adv. Synth. Catal., 2013, 355, 1605.

21 (a) R. Zhu, G. Cheng, C. Jia, L. Xue and X. Cui, J. Org. Chem., 2016, 81, 7539; (b) J. Shen, L. Xue, X. Lin, G. Cheng and X. Cui, Chem. Commun., 2016, 52, 3292; (c) J. Shen, X. Wang, X. Lin, Z. Yang, G. Cheng and X. Cui, Org. Lett., 2016, 18, 1378; (d) G. Cheng, Y. Weng, X. Yang and X. Cui, Org. Lett., 2015, 17, 3790; (e) J. Shen, D. Cai, C. Kuai, Y. Liu, M. Wei, G. Cheng and X. Cui, J. Org. Chem., 2015, 80, 6584; (f) X. Yang, G. Cheng, J. Shen, C. Kuai and X. Cui, Org. Chem. Front., 2015, 2, 366; (g) X. Wang, G. Cheng, J. Shen, X. Yang, M.-e. Wei, Y. Feng and X. Cui, Org. Chem. Front., 2014, 1, 1001; (h) G. Cheng, X. Zeng, J. Shen, X. Wang and X. Cui, Angew. Chem., Int. Ed., 2013, 52, 13265; (i) G. Cheng and X. Cui, Org. Lett., 2013, 15, 1480; (j) J. Shen, G. Cheng and X. Cui, Chem. Commun., 2013, 49, 10641.

22 J.-N. Tan, H. Li and Y. Gu, Green Chem., 2010, 12, 1772. 